\title{
Prolyl isomerase Pin1 expression predicts prognosis in patients with esophageal squamous cell carcinoma and correlates with cyclinD1 expression
}

\author{
MINORU FUKUCHI, YASUYUKI FUKAI, HITOSHI KIMURA, MAKOTO SOHDA, \\ TATSUYA MIYAZAKI, MASANOBU NAKAJIMA, NORIHIRO MASUDA, \\ KATSUHIKO TSUKADA, HIROYUKI KATO and HIROYUKI KUWANO \\ Department of General Surgical Science, Gunma University Graduate School of Medicine, \\ Maebashi, Gunma 371-8511, Japan
}

Received October 3, 2005; Accepted November 16, 2005

\begin{abstract}
Esophageal carcinoma is one of the most lethal tumors, and identification of prognostic factors for patients with this disease is important. Propyl isomerase Pin1 is overexpressed in some human cancers and thought to be an important regulator of cyclinD1. However, the relationships between Pin 1 expression and clinicopathologic features in patients with esophageal squamous cell carcinoma (SCC) have not been explored. Here, we investigated the role of Pin1 in association with cyclinD1 in esophageal SCC progression and its clinicopathological significance. The expressions of Pin1 and cyclinD1 were examined immunohistochemically in surgical specimens from 119 esophageal SCC patients. The expression levels of Pin 1 and cyclinD1 in 6 esophageal SCC-derived cell lines were compared with those in an immortalized human esophageal cell line by Western blotting. Pin1 overexpression was correlated with lymph node metastasis $(\mathrm{P}=0.0384)$, and its expression was related to cyclinD1 expression. Pin1 expression was correlated with poor prognosis in esophageal SCC patients $(\mathrm{P}=0.0044)$, and found to be an independent prognostic factor $(\mathrm{P}=0.0277)$. Pin1 was overexpressed in 5 of 6 esophageal SCC-derived cell lines compared with immortalized esophageal keratinocytes. Moreover, the Pin1 level was correlated with the cyclinD1 level in 4 of the 6 cell lines. In conclusion, Pin 1 expression is correlated with cyclinD1 expression and may be a useful prognostic factor for esophageal SCC.
\end{abstract}

\section{Introduction}

Despite recent progress in cancer diagnosis and treatment, esophageal cancers still have relatively high mortality rates (1). Moreover, lymph node metastasis occurs more frequently in

Correspondence to: Dr Minoru Fukuchi, Department of General Surgical Science, Gunma University Graduate School of Medicine, 3-39-22, Showa-machi, Maebashi, Gunma 371-8511, Japan

E-mail: mfukuchi@med.gunma-u.ac.jp

Key words: Pin1, cyclinD1, esophageal squamous cell carcinoma, immunohistochemistry esophageal cancers than in other gastrointestinal malignancies, thereby resulting in a poor outcome, even in patients detected at an early stage (2,3). However, recent advances in molecular biology have revealed that various oncogenes and tumor suppressor genes are related to the development and progression of esophageal cancer. Amplification of the cyclinDl gene is a well-known genetic change and its overexpression is closely related to the invasiveness of cancer cells as well as the patient outcome $(4,5)$. However, the details of the influence of cyclinD1 on this disease remain unclear.

Phosphorylation of proteins on serine/threonine residues that precede proline (pSer/Thr-Pro) is a major intracellular signaling mechanism for regulating cell proliferation and transformation $(6,7)$. The $\mathrm{pSer} / \mathrm{Thr}$-Pro motifs present in a certain subset of phosphoproteins are specifically isomerized by the peptidyl-prolyl cis-trans isomerase Pin 1 . This post-phosphorylation isomerization can lead to conformational changes in the substrate proteins and show profound effects on their catalytic activities, dephosphorylation, protein-protein interactions and subcellular localization (8-11). Pin 1 is essential for mitotic progression and required for the DNA checkpoint (12-15). Therefore, Pin1 plays an important role in cell cycle regulation.

It has been demonstrated that Pin 1 is overexpressed in some human cancers and that its expression is closely correlated with the level of cyclinD1 in human breast and oral cancers (14-17). Furthermore, Pin 1 expression is correlated with tumor development and poor prognosis in patients with human prostate cancer (18). Up-regulation of Pin1 has been shown to potentiate the function of several oncogenic pathways. Pin1 elevates cyclinDl gene expression by activating the c-jun/AP-1 and $\beta$-catenin/TCF transcription factors $(14,15)$. Taken together, these results suggest that Pin1 in association with cyclinD1 plays important roles in oncogenesis. However, the effects of variations in Pin1 expression in esophageal squamous cell carcinoma (SCC) remain unknown. In the present study, we used immunohistochemistry to examine the relationships between Pin 1 expression and clinicopathologic features in esophageal SCC patients who underwent potentially curative surgery. Moreover, we explored the details of the influence of cyclinD1 in association with Pin1 expression in esophageal SCC. 
A

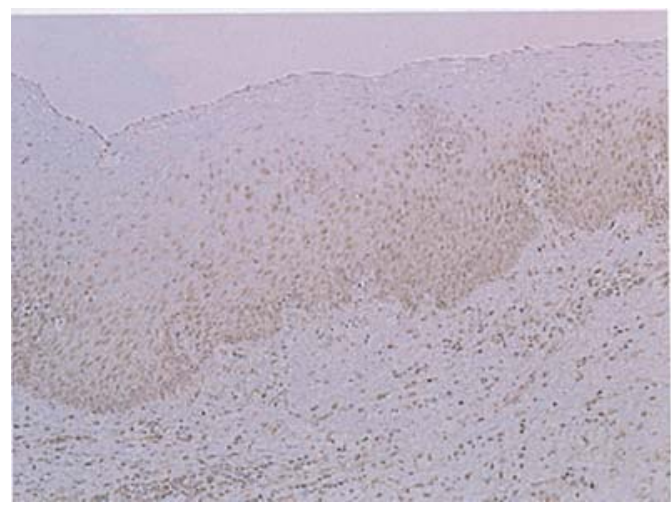

C

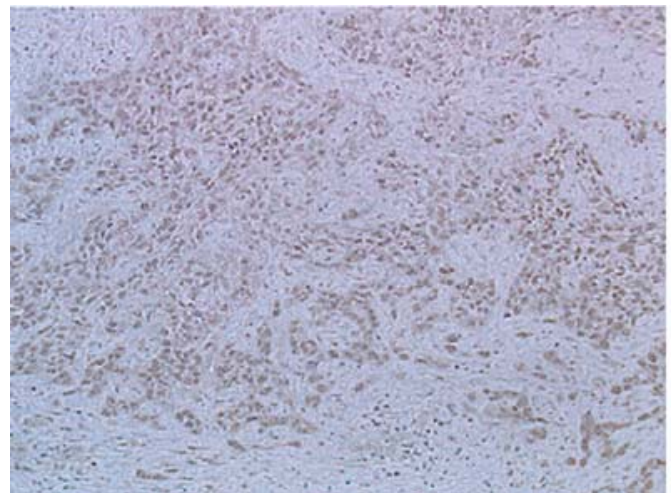

B

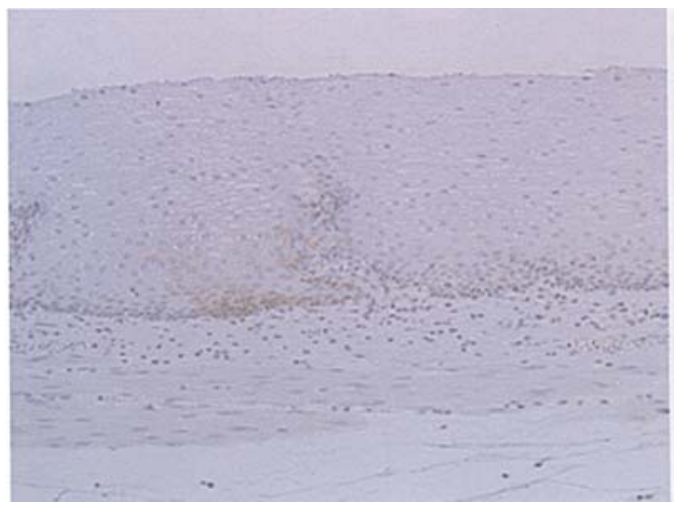

D

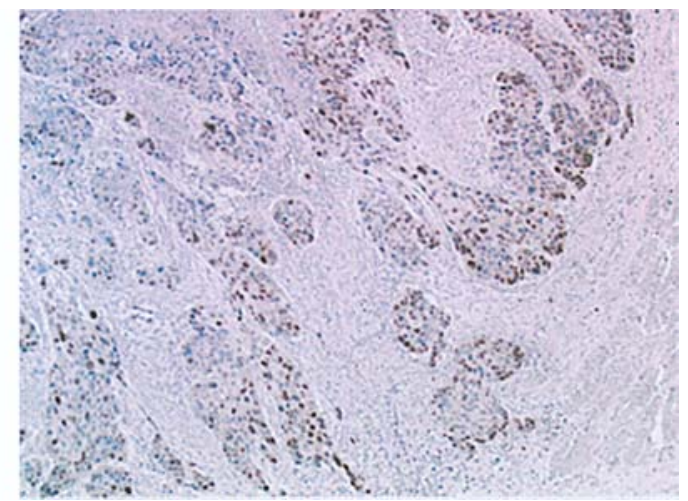

Figure 1. Photographs of tissue sections immunostained for Pin1 and cyclinD1 (x100). (A), Pin1 is predominantly detected in the nuclei of the terminally differentiated basal keratinocytes in normal esophageal epithelium. (B), CyclinD1 is partially detected in the nuclei of cells in the basal regions in normal esophageal epithelium. (C), Pin1 is predominantly present in the cell nuclei and also detected in the cytoplasm at the invasive front of the carcinoma. (D), CyclinD1 is detected in the nuclei of tumor cell nests in esophageal squamous carcinoma.

\section{Materials and methods}

Patients. Surgical specimens were obtained from 119 patients (103 males and 16 females) with esophageal SCC who underwent potentially curative surgery without preoperative therapy at the Department of General Surgical Science, Gunma University Graduate School of Medicine, between 1983 and 2002. The age of the patients ranged from 40 to 78 years with a mean age of 62.2 years. Tumor stage was classified according to the fifth edition of the TNM classification of the International Union Against Cancer (19). All of the distant metastastic lesions were lymph nodes.

Immunohistochemistry for Pinl and cyclinD1. Resected specimens were fixed with $10 \%$ formaldehyde and embedded in paraffin blocks. Immunohistochemical staining of the sections was performed by the standard avidin-biotin peroxidase complex method described previously $(20,21)$. Briefly, the sections were incubated with anti-Pin1 polyclonal antibody (Santa Cruz Biotechnology, Inc., Santa Cruz, CA) at a dilution of 1:200 and anti-cyclinD1 monoclonal antibody (clone P2D11F11, Novocastra Laboratories, Ltd., Newcastle, UK) at a dilution of 1:50 and counterstained lightly with hematoxylin. A negative control was prepared by substituting normal rabbit and mouse serum for each primary antibody. No staining was detected in any control section.

Evaluation of Pin1 and cyclinD1 expression. Pin1 immunostaining was evaluated visually and semi-quantified by two of the authors (M.F. and Y.F.) in a coded manner, and then scored for the degree of expression. Normal squamous mucosa was always used as a positive control to ensure the quality of the immunostaining (18). Pin1 was classified as high (staining in $67-100 \%)$ or low $(0-67 \%)$ based the percentage of the tumor cells that were immunopositive and also the intensity of the staining.

The cyclinD1 staining was classified as high when $>10 \%$ of the tumor cells were positive, and low when $\leq 10 \%$ of the tumor cells were positive, as described in previous studies $(22,23)$.

Cell culture. Six established cell lines derived from esophageal SCC and one immortalized human esophageal cell line were used: TE-series 2, 8, 13, 14 and 15 (gift from Dr T. Nishihira, Tohoku University, Japan) (24), T.T (JCRB0262, gift from Dr K. Takahashi) and CHEK-1 (gift from Dr H. Matsubara). This latter cell line was established by transduction of human papillomavirus type 16 E6/E7 into primary cultures of human esophageal keratinocytes (25). The TE-series and CHEK-1 were cultured in RPMI-1640 medium (Sigma, St. Louis, MO) containing $10 \%$ fetal bovine serum and antibiotics (100 units/ml penicillin and $100 \mu \mathrm{g} / \mathrm{ml}$ streptomycin); T.T was cultured in a 1:1 Dulbecco's modified Eagle's medium and Ham's F-12 medium (Sigma) containing 10\% fetal bovine serum and antibiotics as described above.

Cell extraction and Western blotting. Lysates from exponentially growing cell lines were prepared in a buffer comprising 
20 mM Tris- $\mathrm{HCl}, \mathrm{pH}$ 7.5, $150 \mathrm{mM} \mathrm{NaCl}, 1 \%$ Nonidet P-40, $1 \%$ aprotinin and $1 \mathrm{mM}$ phenylmethylsulfonyl fluoride and subjected to Western blotting, as described previously (20). The protein concentrations were determined with a BCA Protein Assay Kit (Pierce, Rockford, IL, USA). A 30- $\mu \mathrm{g}$ aliquot of protein from each cell line was subjected to electrophoresis on a $10 \%$ Ready-Gel (Bio-Rad, Tokyo, Japan) followed by electroblotting onto a Hybond enhanced chemiluminescence nitrocellulose membrane (Amersham Pharmacia Biotech, Bucks., UK). The proteins were immunoblotted using anti-Pin1 (Santa Cruz Biotechnology) and anti-cyclinD1 (Novocastra Laboratories) antibodies. An anti-ß-actin (Sigma) antibody served as the control.

Statistical analysis. Statistical analysis was performed using the $\chi^{2}$ test, Fisher's exact test, and the Mann-Whitney. Survival curves of the patients were calculated using the Kaplan-Meier method, and analysis was performed using the log-rank test. The prognostic factors were examined by univariate and multivariate analysis (proportional hazard regression model). Statistical significance in this study was set as $\mathrm{P}<0.05$.

\section{Results}

Immunohistochemistry for Pin1 and cyclinD1. In normal squamous epithelium of the esophagus, Pin1 immunostaining was predominantly detected in the nuclei of the terminally differentiated basal keratinocytes (Fig. 1A), and cyclinD1 immunostaining was partially detected in the nuclei of cells in the basal regions (Fig. 1B). In primary esophageal SCC, Pin1 staining was predominantly present in the nucleus but also detected in the cytoplasm (Fig. 1C). In the periphery of tumor cell nests, cyclinD1 staining was detected in the nuclei (Fig. 1D).

Correlations between the Pinl and cyclinD1 expression and the clinicopathologic findings. The mean Pin1 expression in esophageal SCC was $60.2 \%$, while that in the surrounding normal squamous epithelium was $51.2 \%$. Pin1 expression was high in 38 of the 119 (31.9\%) patients, and low in the remaining $81(68.1 \%)$. The correlations between the clinicopathologic characteristics of the esophageal SCC patients and the Pin1 expression in their tumors are summarized in Table I. There was a significant correlation between Pin 1 expression and regional lymph node metastasis $(\mathrm{P}=0.0384)$, but no significant correlations with patient age, gender, tumor location, differentiation, depth of invasion, pathologic stage or distant lymph node metastasis. CyclinD1 expression was high in 62 of the $119(52.1 \%)$ patients and low in the remaining 57 $(47.9 \%)$. There were no significant correlations between cyclinD1 expression and the clinicopathologic characteristics of the esophageal SCC patients (Table II). However, Pin1 expression was correlated with cyclinD1 expression $(\mathrm{P}=0.0146$; Table III).

Prognostic significance of Pinl and cyclinD1. The 5-year survival rate of patients with high Pin1 expression was significantly lower than that of patients with low Pin 1 expression ( 35 vs. $61 \%, \mathrm{P}=0.0044$; Fig. 2A). The 5-year survival rate of patients with high cyclinD1 expression was
Table I. The correlation between clinicopathologic characteristics and Pin1 expression.

\begin{tabular}{|c|c|c|c|c|}
\hline Parameters & $\begin{array}{l}\text { Pin1 low } \\
(n=81)\end{array}$ & $\begin{array}{l}\text { Pin1 high } \\
(n=38)\end{array}$ & Total & P-value \\
\hline $\begin{array}{l}\text { Age (mean } \pm \mathrm{SD} \text {; } \\
\text { yrs })\end{array}$ & $62.6 \pm 1.0$ & $61.3 \pm 1.4$ & & 0.4544 \\
\hline Sex & & & & 0.6077 \\
\hline Male & $71(68.9)$ & $32(31.1)$ & 103 & \\
\hline Female & $10(62.5)$ & $6(37.5)$ & 16 & \\
\hline Location & & & & 0.8676 \\
\hline Upper & $10(62.5)$ & $6(37.5)$ & 16 & \\
\hline Midthoracic & $52(69.3)$ & $23(30.7)$ & 75 & \\
\hline Lower & $19(67.9)$ & $9(32.1)$ & 28 & \\
\hline Differentiation & & & & 0.3398 \\
\hline Well & $19(65.5)$ & $10(34.5)$ & 29 & \\
\hline Moderate & $32(62.7)$ & $19(37.3)$ & 51 & \\
\hline Poor & $30(76.9)$ & $9(23.1)$ & 39 & \\
\hline \multicolumn{5}{|c|}{ TNM classification ${ }^{\mathrm{a}}$} \\
\hline $\mathrm{T}$ & & & & 0.6793 \\
\hline $\mathrm{T} 1$ & $37(74.0)$ & $13(26.0)$ & 50 & \\
\hline $\mathrm{T} 2$ & $10(66.7)$ & $5(33.3)$ & 15 & \\
\hline $\mathrm{T} 3$ & $30(62.5)$ & $18(37.5)$ & 48 & \\
\hline $\mathrm{T} 4$ & $4(66.7)$ & $2(33.3)$ & 6 & \\
\hline $\mathrm{N}$ & & & & 0.0384 \\
\hline N0 & $42(77.8)$ & $12(22.2)$ & 54 & \\
\hline $\mathrm{N} 1$ & $39(60.0)$ & $26(40.0)$ & 65 & \\
\hline M & & & & 0.8900 \\
\hline M0 & $69(68.3)$ & $32(31.7)$ & 101 & \\
\hline M1 & $12(66.7)$ & $6(33.3)$ & 18 & \\
\hline Stage & & & & 0.2693 \\
\hline I & $27(73.0)$ & $10(27.0)$ & 37 & \\
\hline II & $27(75.0)$ & $9(25.0)$ & 36 & \\
\hline III & $15(53.6)$ & $13(46.4)$ & 28 & \\
\hline IV & $12(66.7)$ & $6(33.3)$ & 18 & \\
\hline
\end{tabular}

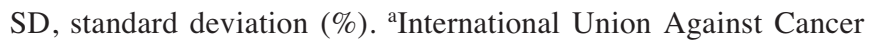
TNM classification of malignant tumors.

significantly lower than that of patients with low cyclinD1 expression (41 vs. $65 \%, \mathrm{P}=0.0318$; Fig. 2B).

Moreover, according to a multivariate analysis using a Cox proportional hazards model, Pin 1 and cyclinD1 were independent prognostic factors of overall survival $(\mathrm{P}=0.0277$ and 0.0211 , respectively; hazard ratios, 2.038 and 2.067, respectively, Table IV).

Pinl and cyclinD1 protein levels in esophageal SCC-derived cell lines. The Pin1 and cyclinD1 protein levels in 6 esophageal 
Table II. The correlation between clinicopathologic characteristics and cyclinD1 expression.

\begin{tabular}{cccc}
\hline Parameters & $\begin{array}{c}\text { CyclinD1 } \\
\text { low } \\
(\mathrm{n}=57)\end{array}$ & $\begin{array}{c}\text { CyclinD1 } \\
\text { high } \\
(\mathrm{n}=62)\end{array}$ & \\
& & & \\
& & & \\
\hline
\end{tabular}

\begin{tabular}{|c|c|c|c|c|}
\hline $\begin{array}{l}\text { Age (mean } \pm S D \text {; } \\
\text { yrs) }\end{array}$ & $63.6 \pm 1.1$ & $60.9 \pm 1.4$ & & 0.0966 \\
\hline Sex & & & & 0.2089 \\
\hline Male & $47(45.6)$ & $56(54.4)$ & 103 & \\
\hline Female & $10(62.5)$ & $6(37.5)$ & 16 & \\
\hline Location & & & & 0.1600 \\
\hline Upper & $5(31.3)$ & $11(68.7)$ & 16 & \\
\hline Midthoracic & $35(46.7)$ & $40(53.3)$ & 75 & \\
\hline Lower & $17(60.7)$ & $11(39.3)$ & 28 & \\
\hline Differentiation & & & & 0.5802 \\
\hline Well & $16(55.2)$ & $13(44.8)$ & 29 & \\
\hline Moderate & $22(43.1)$ & $29(56.9)$ & 51 & \\
\hline Poor & 19 (48.7) & $20(51.3)$ & 39 & \\
\hline \multicolumn{5}{|l|}{ TNM classification ${ }^{a}$} \\
\hline $\mathrm{T}$ & & & & 0.4727 \\
\hline $\mathrm{T} 1$ & $22(44.0)$ & $28(56.0)$ & 50 & \\
\hline $\mathrm{T} 2$ & $10(66.7)$ & $5(33.3)$ & 15 & \\
\hline $\mathrm{T} 3$ & $22(45.8)$ & $26(54.2)$ & 48 & \\
\hline $\mathrm{T} 4$ & $3(50.0)$ & $3(50.0)$ & 6 & \\
\hline $\mathrm{N}$ & & & & 0.2480 \\
\hline No & $29(53.7)$ & $25(46.3)$ & 54 & \\
\hline N1 & $28(43.1)$ & 37 (56.9) & 65 & \\
\hline M & & & & 0.7501 \\
\hline M0 & 49 (48.5) & $52(51.5)$ & 101 & \\
\hline M1 & $8(44.4)$ & $10(55.6)$ & 18 & \\
\hline Stage & & & & 0.7354 \\
\hline I & $17(45.9)$ & $20(54.1)$ & 37 & \\
\hline II & $20(55.6)$ & $16(44.4)$ & 36 & \\
\hline III & $12(42.9)$ & $16(57.1)$ & 28 & \\
\hline IV & $8(44.4)$ & $10(55.6)$ & 18 & \\
\hline
\end{tabular}

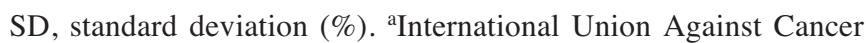
TNM classification of malignant tumors.

SCC-derived cell lines were compared with those in an immortalized esophageal keratinocyte cell line (CHEK-1) by Western blotting. Compared with CHEK-1, Pin1 was expressed at a high level in 5 of the 6 esophageal SCC cell lines, with TE-13 being the exception. Moreover, cyclinD1 was expressed at a high level in 2 cell lines (TE-2 and TE-13), and at a slightly higher level in 3 cell lines (TE-8, TE-15 and T.T). Four of the cell lines (TE-2, TE-8, TE-15 and T.T) showed a positive relationship between the Pin1 and cyclinD1 expression levels, while the other 2 cell lines (TE-13 and TE-14) did not (Fig. 3).
Table III. The correlation between Pin 1 and cyclinD1 expression.

\begin{tabular}{lccc}
\hline & \multicolumn{2}{c}{ Pin1 } & \\
\cline { 2 - 3 } & High & Low & P-value \\
\hline $\begin{array}{l}\text { CyclinD1 } \\
\text { High }\end{array}$ & 26 & 36 & \\
Low & 12 & 45 & 0.0146 \\
\hline
\end{tabular}
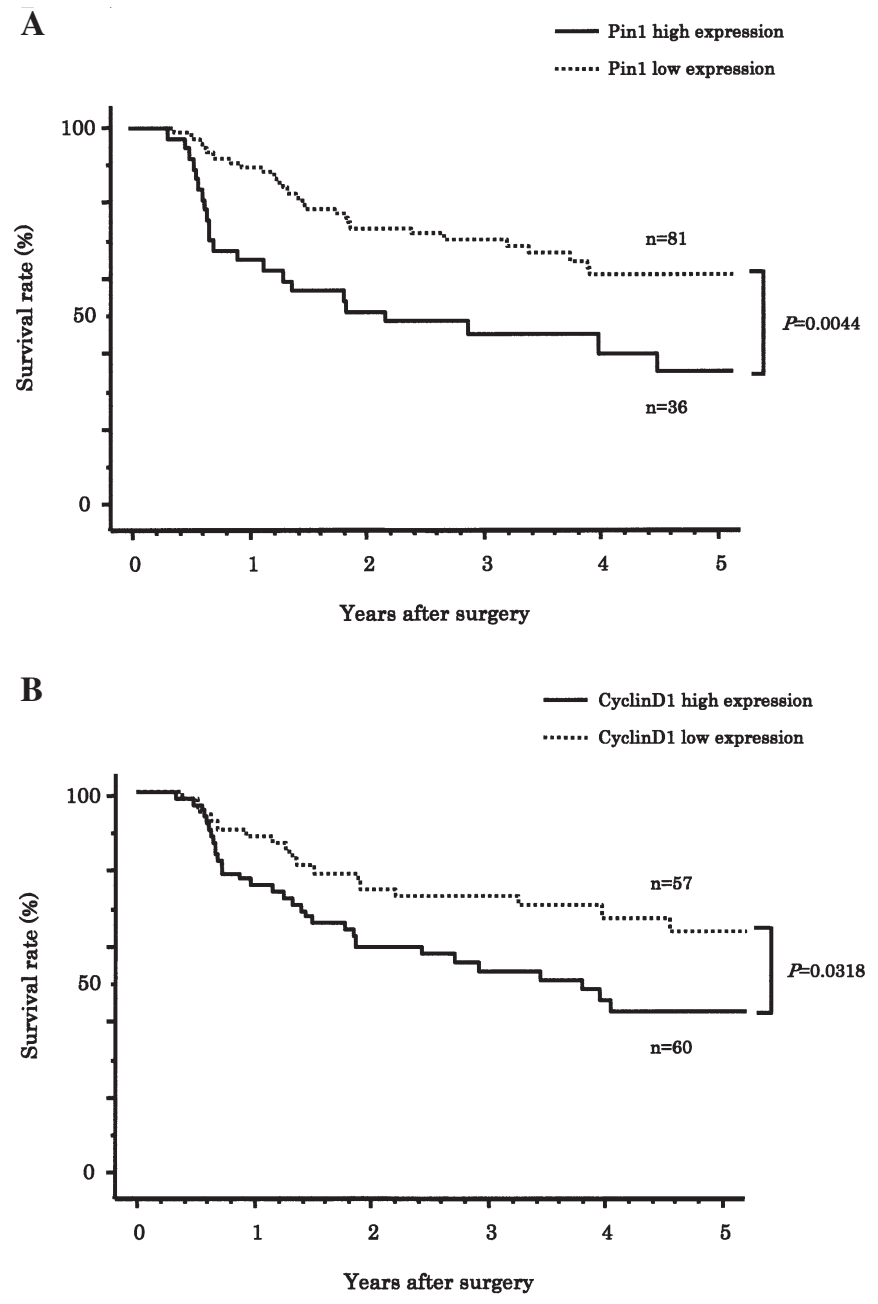

Figure 2. Overall postoperative survival rates according to the Pin 1 and cyclinD1 expression. The P-value was determined using the log-rank test. (A), Patients with high Pin1 expression have a significantly more unfavorable prognosis than patients with low Pin1 expression (5-year survival rates: high expression, $35 \%$ vs. low expression, $61 \%, \mathrm{P}=0.0044)$. (B), Patients with high cyclinD1 expression have a significantly more unfavorable prognosis than patients with low cyclinD1 expression (5-year survival rates: high expression, $41 \%$ vs. low expression, $65 \%, \mathrm{P}=0.0318$ ).

\section{Discussion}

Pin1 has been shown to play an important role in oncogenesis (14-18). It is overexpressed in human breast and oral cancers, 
Table IV. Multivariate analysis of risk factors affecting survival rate.

\begin{tabular}{lllr}
\hline Risk factor & Reference factor & Hazards ratio & P-value \\
\hline Histological grading $^{\mathrm{a}}$ & G1, G2 vs. G3 & 1.920 & 0.0377 \\
Primary tumor (T) $^{\mathrm{b}}$ & T1, 2 vs. T3, 4 & 3.646 & 0.0006 \\
Regional lymph nodes metastasis (N) $^{\mathrm{a}}$ & Negative vs. Positive & 5.719 & 0.0198 \\
Distant lymph nodes metastasis (M) $_{\text {Stage grouping }}^{\mathrm{a}}$ & Negative vs. Positive & 2.058 & 0.0477 \\
CyclinD1 & I vs. II, III, IV & 0.680 & 0.6801 \\
Pin1 & Negative vs. Positive & 2.067 & 0.0211 \\
\hline
\end{tabular}

anternational Union Against Cancer TNM classification of malignant tumors. ${ }^{\mathrm{b}} \mathrm{G} 1$, well differentiated; G2, moderately differentiated; G3, poorly differentiated.

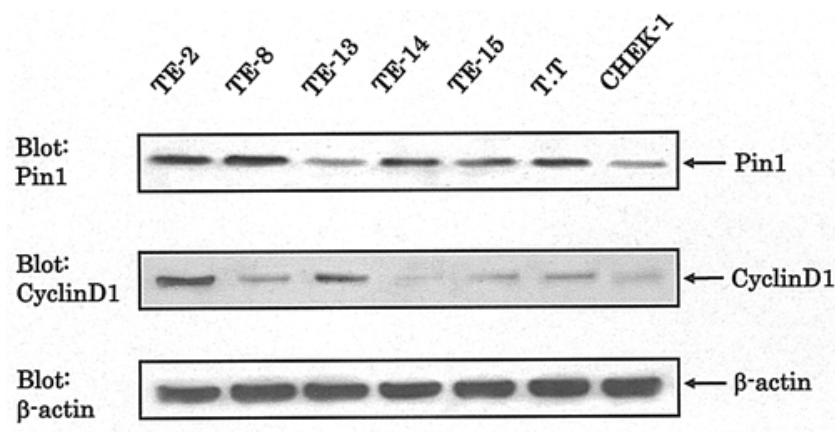

Figure 3. Western blotting of cell extracts from 6 esophageal squamous carcinoma-derived cell lines and an immortalized human esophageal cell line (CHEK-1). The expressions of Pin1 (18 kDa), cyclinD1 (36 kDa) and $\beta$-actin (42 kDa; control) are shown.

and correlated with tumor development and poor prognosis in patients with human prostate cancer (16-18). However, the effects of variations in Pin1 expression in esophageal SCC remain unclear. Therefore, we used immunohistochemistry to investigate the correlations between Pin1 expression and pathologic tumor variables in patients with esophageal SCC. Pin1 was predominantly present in the nuclei of esophageal SCC cells, and higher at the invasive front of tumors where the proliferative activity is high (26). Comparisons of Pin1 expression and clinicopathologic features revealed that Pin1 overexpression was positively correlated with lymph node metastasis $(\mathrm{P}=0.0384)$, but not with any other commonly used clinicopathologic features. Moreover, patients with high Pin1 expression had a significantly more unfavorable prognosis $(\mathrm{P}=0.0044)$, and a multivariate analysis revealed that Pin1 expression was an independent prognostic factor $(\mathrm{P}=0.0277)$. Furthermore, Western blotting showed that Pin1 was overexpressed in 5 of 6 esophageal SCC-derived cell lines compared with the level in immortalized esophageal keratinocytes. These results suggest that high levels of Pin1 expression may influence tumor progression and lead to a poor prognosis in esophageal SCC.

The strong relationship between the level of Pin1 expression and the clinical outcome of esophageal SCC suggests that
Pin1 is involved in the progression of this disease. Pin1 overexpression activates multiple steps in oncogenic signaling pathways. For example, Pin1 collaborates with Ras signaling to increase the transcriptional activity of c-Jun toward cyclinD1 (14). Pin1 also activates $\beta$-catenin, which can induce the transcription of both cyclinD1 and c-Myc (15). Furthermore, Pin 1 can directly bind and stabilize cyclinD1 (27). Pin1 is also involved in the DNA damage response, through modulation of $\mathrm{p} 53$ functions upon genotoxic stress $(28,29)$. Although cyclinD1 and p53 are well-known to be associated in tumor progression and poor prognosis in patients with esophageal SCC, the details of their influences, as well as the effects of Pin1, remain unclear.

Initially, we hypothesized that cyclinD1 expression may serve as a prognostic factor, since amplification and overexpression of cyclinD1 can allow cancer cells to traverse the G0 to G1 and/or G1 to S transitions. Amplification of the cyclinD1 gene has been reported in $22-58 \%$ of esophageal carcinomas, and this can provide useful prognostic information (30-34). Moreover, cyclinD1 has been reported to be involved in tumor progression of esophageal carcinoma, and its overexpression detected by immunohistochemistry is a useful prognostic factor (32). Similar to the findings of previous reports, our data demonstrate that cyclinD1 expression is correlated with poor prognosis in esophageal SCC patients $(\mathrm{P}=0.0318)$ and acts as an independent prognostic factor $(\mathrm{P}=0.0211)$, although no significant correlations were observed between cyclinD1 expression and the clinicopathologic characteristics. However, the molecular mechanisms responsible for cyclinD1 overexpression remain unknown. In the present study, Pin 1 expression showed a positive correlation with cyclinD1 expression in esophageal SCC by immunohistochemistry $(\mathrm{P}=0.0146)$ and in 4 of 6 cell lines by Western blotting. Moreover, considering previous findings that Pin1 induces cyclinD1 gene expression (14-18), it is likely that Pin1 up-regulates the expression level of cyclinD1 and is involved in tumor progression of esophageal SCC. On the other hand, our data showed that Pin1 expression was not correlated with p53 expression by either immunohistochemistry or Western blotting, although it is known to modulate p53 activation during the DNA damage response (data not shown) 
$(28,29)$. However, since p53 plays an important role in oncogenesis, the role of Pin1-mediated p53 activation in esophageal carcinogenesis needs to be clarified in future studies.

In conclusion, Pin 1 overexpression may affect the tumor development of esophageal SCC, especially in relation to cyclinD1 expression, and be associated with poor prognosis. Although Pin 1 may be the most important regulator of cyclinD1 in esophageal SCC, it also regulates the activities of other proteins $(35,36)$. Therefore, further studies on the effects of Pin 1 are necessary to elucidate the participation of other Pin1-regulated factors in aggressive esophageal SCC.

\section{Acknowledgements}

We would like to thank Dr T. Nishihira for the TE-series cell lines, Dr K. Takahashi for the T.T cell line and Dr H. Matsubara for the CHEK-1 cell line.

\section{References}

1. Sugimachi K, Watanabe M, Sadanaga N, Ikebe M, Kitamura K, Mori $\mathrm{M}$ and Kuwano $\mathrm{H}$ : Recent advances in the diagnosis and surgical treatment of patients with carcinoma of the esophagus. J Am Coll Surg 178: 363-368, 1994.

2. Kodama M and Kakegawa T: Treatment of superficial cancer of the esophagus: a summary of responses to a questionnaire on superficial cancer of the esophagus in Japan. Surgery 123: 432-439, 1998.

3. Kuwano H, Masuda N, Kato H and Sugimachi K: The subepithelial extension of esophageal carcinoma for determining the resection margin during esophagectomy: a serial histopathologic investigation. Surgery 131: S14-S21, 2002.

4. Shimada Y, Imamura M, Shibagaki I, Tanaka H, Miyahara T, Kato $\mathrm{M}$ and Ishizaki $\mathrm{K}$ : Genetic alterations in patients with esophageal cancer with short- and long-term survival rates after curative esophagectomy. Ann Surg 226: 162-168, 1997.

5. Watanabe M, Kuwano H, Tanaka S, Toh Y, Masuda H and Sugimachi K: A significant morphological transformation is recognized in human esophageal cancer cells with an amplification/overexpression of the cyclin D1 gene. Int J Oncol 15: 1103-1108, 1999.

6. Blume-Jensen P and Hunter T: Oncogenic kinase signalling. Nature 411: 355-365, 2001.

7. Hanahan D and Weinberg RA: The hallmarks of cancer. Cell 100: 57-70, 2000.

8. Lu KP, Hanes SD and Hunter T: A human peptidyl-prolyl isomerase essential for regulation of mitosis. Nature 380: 544-547, 1996.

9. Lu KP, Liou YC and Zhou XZ: Pinning down proline-directed phosphorylation signaling. Trends Cell Biol 12: 164-172, 2002.

10. Yaffe MB, Schutkowski M, Shen M, Zhou XZ, Stukenberg PT, Rahfeld JU, Xu J, Kuang J, Kirschner MW, Fischer G, Cantley LC and Lu KP: Sequence-specific and phosphorylation-dependent proline isomerization: a potential mitotic regulatory mechanism. Science 278: 1957-1960, 1997.

11. Ranganathan R, Lu KP, Hunter T and Noel JP: Structural and functional analysis of the mitotic rotamase Pin1 suggests substrate recognition is phosphorylation dependent. Cell 89: 875-886, 1997.

12. Shen M, Stukenberg PT, Kirschner MW and Lu KP: The essential mitotic peptidyl-prolyl isomerase Pin1 binds and regulates mitosis-specific phosphoproteins. Genes Dev 12: 706-720, 1998

13. Winkler KE, Swenson KI, Kornbluth S and Means AR: Requirement of the prolyl isomerase Pin 1 for the replication checkpoint. Science 287: 1644-1647, 2000.

14. Wulf GM, Ryo A, Wulf GG, Lee SW, Niu T, Petkova V and $\mathrm{Lu}$ KP: Pin 1 is overexpressed in breast cancer and cooperates with Ras signaling in increasing the transcriptional activity of c-Jun towards cyclin D1. EMBO J 20: 3459-3472, 2001.

15. Ryo A, Nakamura M, Wulf G, Liou YC and Lu KP: Pin1 regulates turnover and subcellular localization of $ß$-catenin by inhibiting its interaction with APC. Nat Cell Biol 3: 793-801, 2001.
16. Miyashita H, Mori S, Motegi K, Fukumoto M and Uchida T: Pin1 is overexpressed in oral squamous cell carcinoma and its levels correlate with cyclin D1 overexpression. Oncol Rep 10: 455-461, 2003.

17. Miyashita H, Uchida T, Mori S, Echigo S and Motegi K: Expression status of Pin 1 and cyclins in oral squamous cell carcinoma: Pin1 correlates with Cyclin D1 mRNA expression and clinical significance of cyclins. Oncol Rep 10: 1045-1048, 2003.

18. Ayala G, Wang D, Wulf G, Frolov A, Li R, Sowadski J, Wheeler TM, Lu KP and Bao L: The prolyl isomerase Pin1 is a novel prognostic marker in human prostate cancer. Cancer Res 63: 6244-6251, 2003.

19. Sobin $\mathrm{LH}$ and Wittekind $\mathrm{CH}$ (eds). International Union Against Cancer. TNM Classification of Malignant Tumors. 5th edition. Wiley, New York, 1997.

20. Fukuchi M, Nakajima M, Fukai Y, Miyazaki T, Masuda N, Sohda M, Manda R, Tsukada K, Kato H and Kuwano H: Increased expression of c-Ski as a co-repressor in transforming growth factor- $\beta$ signaling correlates with progression of esophageal squamous cell carcinoma. Int J Cancer 108: 818-824, 2004.

21. Masuda N, Kato H, Nakajima T, Sano T, Kashiwabara K, Oyama T and Kuwano H: Synergistic decline in expressions of p73 and p21 with invasion in esophageal cancers. Cancer Sci 94: 612-617, 2003.

22. Itami A, Shimada Y, Watanabe G and Imamura M: Prognostic value of p27(Kip1) and CyclinD1 expression in esophageal cancer. Oncology 57: 311-317, 1999.

23. Shiozaki H, Doki Y, Yamana H and Isono K: A multiinstitutional study of immunohistochemical investigation for the roles of cyclin D1 and E-cadherin in superficial squamous cell carcinoma of the esophagus. J Surg Oncol 79: 166-173, 2002.

24. Nishihira T, Hashimoto Y, Katayama M, Mori S and Kuroki T: Molecular and cellular features of esophageal cancer cells. J Cancer Res Clin Oncol 119: 441-449, 1993.

25. Sashiyama H, Shino Y, Sakao S, Shimada H, Kobayashi S, Ochiai $\mathrm{T}$ and Shirasawa H: Alteration of integrin expression relates to malignant progression of human papillomavirus-immortalized esophageal keratinocytes. Cancer Lett 177: 21-28, 2002.

26. Kuwano H, Saeki H, Kawaguchi H, Sonoda K, Kitamura K, Nakashima H, Toh Y and Sugimachi K: Proliferative activity of cancer cells in front and center areas of carcinoma in situ and invasive sites of esophageal squamous-cell carcinoma. Int $\mathbf{J}$ Cancer 78: 149-152, 1998.

27. Liou YC, Ryo A, Huang HK, Lu PJ, Bronson R, Fujimori F, Uchida T, Hunter T and Lu KP: Loss of Pin1 function in the mouse causes phenotypes resembling cyclin D1-null phenotypes. Proc Natl Acad Sci USA 99: 1335-1340, 2002.

28. Zheng H, You H, Zhou XZ, Murray SA, Uchida T, Wulf G, Gu L, Tang X, Lu KP and Xiao ZX: The prolyl isomerase Pin 1 is a regulator of p53 in genotoxic response. Nature 419: 849-853, 2002.

29. Zacchi P, Gostissa M, Uchida T, Salvagno C, Avolio F, Volinia S, Ronai Z, Blandino G, Schneider C and Del Sal G: The prolyl isomerase Pin 1 reveals a mechanism to control p53 functions after genotoxic insults. Nature 419: 853-857, 2002.

30. Jiang W, Kahn SM, Tomita N, Zhang YJ, Lu SH and Weinstein IB: Amplification and expression of the human cyclin D gene in esophageal cancer. Cancer Res 52: 2980-2983, 1992.

31. Adelaide J, Monges G, Derderian C, Seitz JF and Birnbaum D: Oesophageal cancer and amplification of the human cyclin D gene CCND1/PRAD1. Br J Cancer 71: 64-68, 1995.

32. Naitoh H, Shibata J, Kawaguchi A, Kodama M and Hattori T: Overexpression and localization of cyclin D1 mRNA and antigen in esophageal cancer. Am J Pathol 146: 1161-1169, 1995.

33. Jiang W, Zhang YJ, Kahn SM, Hollstein MC, Santella RM, Lu SH, Harris CC, Montesano R and Weinstein IB: Altered expression of the cyclin D1 and retinoblastoma genes in human esophageal cancer. Proc Natl Acad Sci USA 90: 9026-9030, 1993.

34. Roncalli M, Bosari S, Marchetti A, Buttitta F, Bossi P, Graziani D, Peracchia A, Bonavina L, Viale G and Coggi G: Cell cyclerelated gene abnormalities and product expression in esophageal carcinoma. Lab Invest 78: 1049-1057, 1998.

35. Zhou XZ, Kops O, Werner A, Lu PJ, Shen M, Stoller G, Kullertz G, Stark M, Fischer G and Lu KP: Pin1-dependent prolyl isomerization regulates dephosphorylation of Cdc25C and tau proteins. Mol Cell 6: 873-883, 2000.

36. Mantovani F, Piazza S, Gostissa M, Strano S, Zacchi P, Mantovani R, Blandino G and Del Sal G: Pin 1 links the activities of c-Abl and p300 in regulating p73 function. Mol Cell 14: 625-636, 2004. 